\title{
Unethical, a guilty secret, and still crazy after all these years
}

\author{
Fiona Godlee editor in chief, BMJ
}

It's now routine practice in most developed countries to ask patients about their experiences of healthcare, and patients and staff would reasonably expect this information to be used to improve care. Recent news that some patient reviews were in fact entered by NHS staff will do little to boost confidence in the process (doi:10.1136/bmj.g2279). Angela Coulter and colleagues add their own rather depressing account of the current situation (doi:10.1136/bmj.g2225). Around the world we are busy, it seems, collecting data of all sorts on patients' experiences, but the quality and types of data vary widely, making it hard to analyse and harder still to reap reliable conclusions. As a result, nothing changes. There may be other reasons: busyness, inertia, and lack of leadership, training, and capacity for implementing change.

As a group, doctors don't come out of this very well. The evidence cited in Coulter and colleagues' article suggests that, when confronted with criticism, we tend to be defensive, uninterested, or mistrustful of the data. The authors leave us in no doubt that this is a bad thing. "It is unethical to ask patients to comment on their experiences if these comments are going to be ignored," they say. They worry that we are failing to exploit the large databases of national survey results and the growing collections of narrative accounts from patients. As well as calling for more funding for research in this area, their article describes a strategic approach to improving patients' experience. This will be one of many aspects of quality improvement for discussion in Paris at next month's International Forum on Quality and Safety in Healthcare, co-hosted by the $B M J$ and the Institute for Healthcare Improvement (http://internationalforum. bmj.com/home).

Wikipedia used to be a guilty secret for many of us. As doctors and academics we may have used it but wouldn't tend to admit this in public. Things have changed. Most people I ask now freely admit to using Wikipedia, often going to it first as a starting point, even for clinical questions. But a paper this week indicates that some of us are taking this too far, now using Wikipedia not only for background information but citing it as a reference in journal articles. Dylan Bould and colleagues found more than 1400 health science articles that cited Wikipedia (doi:10.1136/bmj.g1585).

Lane Rasberry is "Wikipedian in residence" at Consumer Reports. In his linked editorial he explains why this is bad practice (doi:10.1136/bmj.g1819). Wikipedia is a tertiary information source. It makes great efforts to ensure that its content is referenced to primary and secondary sources, and authors should use these. Journals should be cautious about publishing papers that cite Wikipedia, he says. Of the 2049 citations to Wikipedia identified by Bould and colleagues, 13 $(0.6 \%)$ were in four $B M J$ articles, including nine in one research paper about "how citation distortions create unfounded authority” (doi:10.1136/bmj.b2680). Rather ironic. Anyway, this is not good, and we will stop.

And now it's farewell to Des Spence. After eight years as the $B M J$ 's weekly columnist he has decided to "throw in the towel." His columns have been, as he says in his final one this week, a blast of "dissent against the prevailing wisdom" (doi:10.1136/ bmj.g2343). He has offended many but inspired far more with his unflinching and informed critique of medicine's many wrongheaded ways. He has been the conscience of the profession and the spirit of the $B M J$. We hope one day he will be back "to slug it out for a couple more rounds." But in the meantime we and many readers are grateful that he has remained, like Paul Simon, still crazy after all these years. Thanks, Des.

Cite this as: BMJ 2014;348:g2396

๑ BMJ Publishing Group Ltd 2014 